\title{
- \\ Relíquias da Academia \\ Nacional de Medicina
}

\author{
por \\ Carlos Alberto Basilio de Oliveira', Giovanni Guido Cerri², Paula Padilha Cerqueira ${ }^{3}$, \\ Michele de Almeida Silva ${ }^{4}$ \& Cláudio Tadeu Daniel-Ribeiro ${ }^{5}$
}

${ }^{1}$ Acadêmico Titular e Diretor da Biblioteca Alfredo Nascimento - E-mail: basiliopatologia@br.inter.net, ${ }^{2}$ Acadêmico Titular e Diretor do Museu Inaldo de Lyra Neves-Manta - E-mail: giovanni_cerri@uol. com.br, ${ }^{3}$ Arquivista - E-mail: arquivo@anm.org. br, ${ }^{4}$ Bibliotecária - E-mail: biblioteca@anm.org.br $\&{ }^{5}$ Acadêmico Titular e Diretor do Arquivo Sergio d'Avila Aguinága - E-mail: malaria@fiocruz.br, da Academia Nacional de Medicina.

Em comum acordo, os Diretores de Arquivo (Cláudio Tadeu Daniel-Ribeiro), Biblioteca (Carlos Alberto Basílio de Oliveira), e Museu (Giovanni Guido Cerri) do Centro da Memória Médica (CMM) da Academia Nacional de Medicina (ANM) decidiram eleger e divulgar mensalmente uma Relíquia da ANM escolhida em rodízio entre aquelas do Arquivo Sergio d'Avila Aguinága, da Biblioteca Alfredo Nascimento e do Museu Inaldo de Lyra Neves-Manta. Em cada número (trimestral) dos Anais da ANM será publicado um artigo contendo as fotos da três Relíquias do trimestre, uma relativa a cada Unidade do CMM, com um pequeno trecho descrevendo suas origens e importância.
Nesta primeira edição das Relíquias, o Arquivo Sergio d'Avila Aguinága apresenta um de seus mais preciosos documentos: a ata de fundaçáo da Academia Nacional de Medicina. Preservado por quase dois séculos, esse raro item documental, eternizado em um fac-símile em latáo, exposto no Museu do CMM, ilustra os desígnios da instituição ao descrever os objetivos de criação da ANM, bem como reflete nosso propósito e compromisso de documentação da história da Casa e da medicina brasileira.

A ata de fundação da, então, Sociedade de Medicina do Rio de Janeiro, de 30 de junho de 1829, foi assinada pelos 17 membros fundadores, tendo como primeiro Presidente da instituição o médico e cirurgião Joaquim Cândido Soares de Meirelles (Fig. 1). No documento consta o primeiro estatuto que estabelecia os objetivos filantrópicos; melhoria do exercício da medicina, o avanço tecnológico e a colaboração com o governo nas questôes de saúde pública, o que corresponderia, na atualidade, a funçóes do 
Ministério da Saúde. Seus objetivos seguem inalterados desde então.

Destaca-se, no texto manuscrito a seguinte passagem sobre a missáo da ANM, criada “... especialmente para responder às perguntas do Governo sobre tudo o que interessar à saúde pública e principalmente sobre as epidemias, as moléstias de certos países, as epizootias, os diferentes casos de medicina legal, a propagaçáo da vacina $\mathrm{e}$ investigaçóes que puderem concorrer para o progresso da arte de curar" (o grifo é nosso).

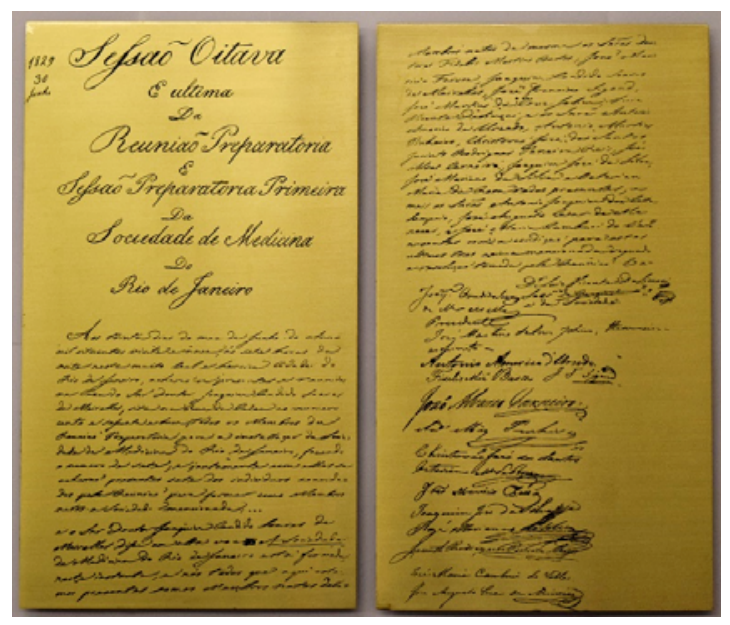

Figura 1 - Relíquia do Arquivo: Ata da fundação da Academia Nacional de Medicina (entấo Sociedade de Medicina Rio de janeiro). Facsímile em latáo, exposto no Museu do Centro da Memória Médica

As peças do Museu e da Biblioteca homenageiam René (Théophile-Hyacinthe) Laënnec (1781-1826). Laënnec, o "pai da medicina torácica", graduou-se em medicina, em 1804, no Hôpital de la Charité, em Paris. Em 1806, começou a atuar como médico do Hôpital Necker, tornando-se médico chefe em 1816. Foi no Hôpital Necker que Laënnec inventou o estetoscópio (Fig. 2), em 1819.

$\mathrm{O}$ instrumento, que permite ouvir sons no interior do corpo humano, é hoje símbolo da medicina clínica. Sua criação e o desenvolvimento da técnica da auscultação possibilitaram um maior conhecimento das doenças torácicas, principalmente pulmonares, e da etiopatogenia das moléstias ao correlacionar dados clínicos com achados de necrópsias.
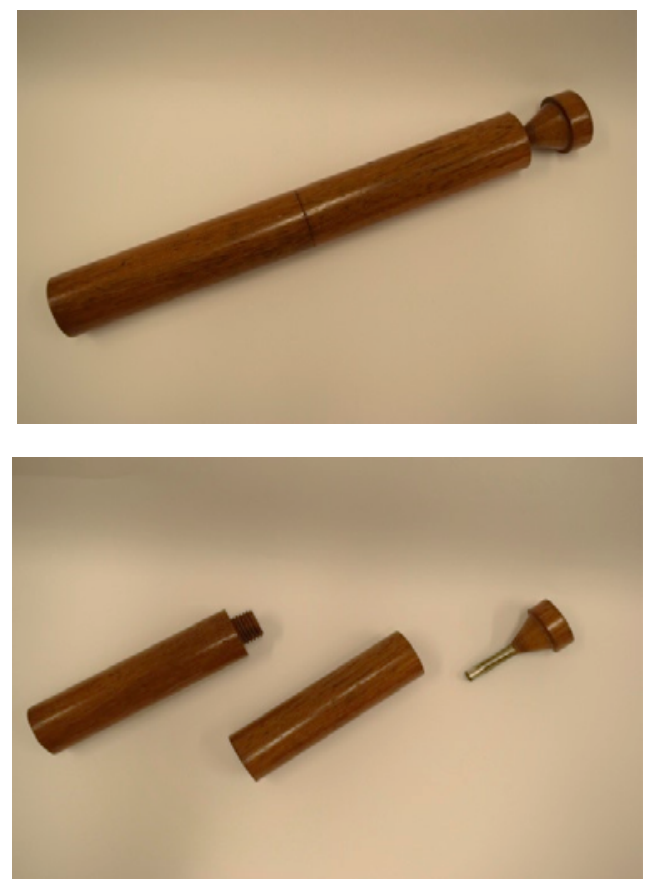

Figura 2 - Relíquia do Museu: Estetoscópio de Laënnec, Séc. XIX. Canudo de madeira, medindo $34 \mathrm{~cm}$ de comprimento, perfurado no sentido do grande eixo, tendo numa extremidade 
uma peça cônica que a ele se adapta por um tubo metálico.

A cópia do estetoscópio original de Laënnec, exposta no Museu Inaldo de Lyra Neves-Manta, veio de Paris trazida pelo Dr. João Fernandes Tavares no século XIX, que a doou à ANM em 1898. Embora essa data seja quase 70 anos após a criação da ANM, os registros da ficha catalográfica da peça revelam que ela foi a primeira peça do Museu, criado, de fato, em 18 de abril daquele ano, como "Museu AnátomoPatológico de Curiosidades Médicas". O Dr. Tavares, designado pelo povo com o cognome de Doutor Canudo, pelo uso que fazia desse instrumento, foi Conselheiro dos Imperadores D. Pedro I e D. Pedro II. A importância dessa Relíquia para a ANM e para a medicina brasileira pode ser ilustrada pelo número de vezes que Instituição a cedeu em empréstimo, principalmente ao longo do século XX, incluindo a Rede Globo e a exposiçóes na Fiocruz.

Com os conhecimentos adquiridos com o uso do seu estetoscópio, Laënnec escreveu e publicou, em Paris em 1819, o famoso De l'auscultation médiate ou Traité du Diagnostic des maladies des poumons et du coeur, que traz na — introdução - a descrição do momento em que, com base no princípio da acústica, Laënnec enrola uma lâmina de papel na forma de um cilindro, encostando uma extremidade na região do coração do paciente e posicionando a outra na orelha.
Com esta experiência percebe, surpreso, que os sons do coração eram mais claros do que com a ausculta imediata com o ouvido encostado no tórax do paciente.

A $4^{a}$ edição da obra, revista e consideravelmente aumentada, foi publicada com o nome de Traité de l'auscultation médiate, et des maladies des poumons et $d u$ coeur, em Bruxelas, Bélgica, em 1837 (quando a nossa quase bicentenária ANM tinha apenas oito anos), e obteve maior sucesso de vendas que a $1^{\text {a }}$ Edição lançada em 1819 em Paris. É um exemplar desta edição, póstuma, que se encontra na Biblioteca (Fig. 3).

Esta Relíquia da Biblioteca Alfredo Nascimento está descrita no "Catálogo de Obras Raras" do setor e consta nos registros da Biblioteca Nacional como um dos únicos exemplares desta edição em instituiçôes do país.

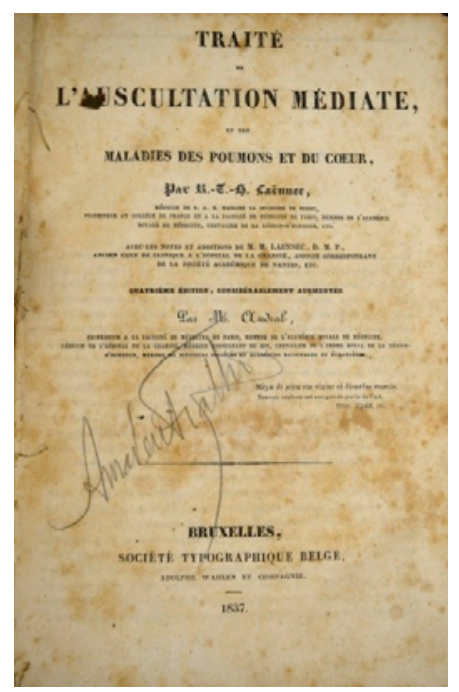




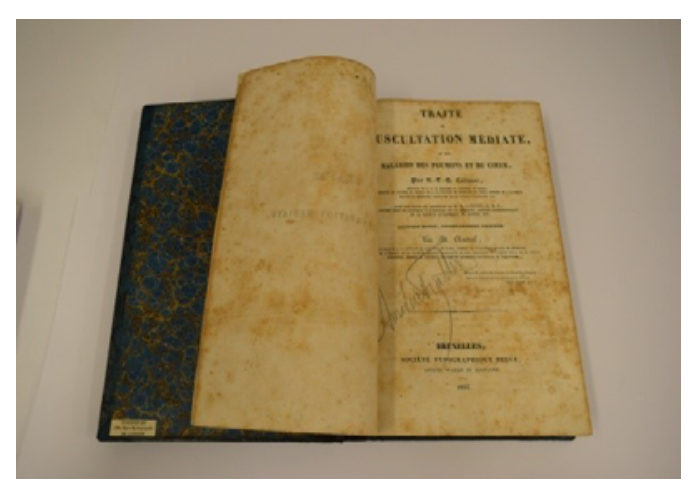

Figura 3 - Relíquia da Biblioteca: Laënnec, René Théophile Hyacinthe, Traité de l'auscultation médiate, et des maladies des poumons et du coeur. 4 ed. considérablement augmentée. Bruxelles, A. Wahlen: Société Typographique Belge, 1837.

\section{Conclusóes}

Este primeiro Relíquias da ANM atevese a três dos principais itens dos três setores - Arquivo, Biblioteca e Museu - ; do Centro da Memória Médica. A Ata de criação da Academia Nacional de Medicina, o estetoscópio e o Tratado de Ausculta de Laënnec ilustram a pujança do acervo da Instituiçáo, doado em sua maioria pelos Acadêmicos e grandes cientistas nacionais desde o império. $\mathrm{O}$ acervo guarda e conserva parcela importante da história da medicina do país que pode ser contada parcialmente pelos documentos, instrumentos médicos e científicos, livros, medalhas, mobiliário, objetos e selos, dentre outros, que estão disponíveis no CMM da ANM e documentam o avanço científico-tecnológico nacional do século XIX até o século XXI.

\section{Agradecimentos}

Os autores são gratos aos Acadêmicos José Galvão Alves e Arno Von Ristow, Editor e Coeditor dos Anais da ANM, respectivamente, por terem acolhido a ideia da criação desta Secçáo como publicaçáo regular do periódico, e ao Acadêmico Carlos Antonio Mascia Gottschall, pela generosa iniciativa pessoal de restauro do livro de Laënnec, da propriedade da ANM. 